\title{
Plankton Biomass in Highly Eutrophic Water and Optimum Physico-Chemical Parameters Supported Aquaculture Production in Buhi Lake: A Preliminary Study
}

\author{
Sandy Rey B. Bradecina*, Mikka Ella M. Cabrera \\ Central Bicol State University of Agriculture, Calabanga Campus \\ *Corresponding Author: Sandy Rey B. Bradecina, Central Bicol State University of Agriculture, Calabanga \\ Campus, Philippines.
}

\begin{abstract}
Sustainable aquaculture in Buhi Lake depends on the availability of food and good water quality. The availability of natural foods such as plankton can also be considered as determining factor for the ideal stocking density and stocking period of tilapia in Lake Cage culture.

This paper investigated the relationship of plankton biomass to the monthly production of farmed tilapia in Lake Buhi. Four sampling stations were designated based on the characteristics, cage concentration and fish kill history. Plankton samples were collected and measured gravimetrically in grams per cubic meter $(\mathrm{g} / \mathrm{m} 3)$ unit. Monthly production of tilapia was collected using key informant interview covering fish brokers and fish farmers following Participatory Rapid Resource Appraisal method. Parameters of water quality in the sites were monitored using water data logger. Data were analysed using ANOVA and descriptive statistics.

Results showed relationship of plankton biomass within sampling stations were not significant implying that plankton biomass within sampling stations did not differ. However, plankton biomass showed a simultaneous increase with the production of culture tilapia within sampling months with high positive correlation (0.94 coefficients) which indicatively suggest increases in plankton biomass directly influence tilapia production in cages. Physico-chemical parameters such as DO and temperature are within the optimum range. The data demonstrated that the water of Lake Buhi is considered as highly eutrophic due to the presence of high level of plankton biomass. The optimum physico-chemical parameters of water supported the requirement for its aquaculture production.
\end{abstract}

Keywords: Plankton biomass, Culture Tilapia, Physico-chemical parameters.

\section{INTRODUCTION}

Lake Buhi is the main source of aquaculture in Buhi which formed by a strong earthquake caused the side of Mt. Iriga which is now Mt. Asog to collapse and resulted a natural dam on small streams in 1641.The lake became the home of the world's smallest commercial fish Sinarapan (Mistichthysluzonensis) (Gindelberger 1981) and later on became the center of tilapia cage farming industry in Bicol Region.

The possible reason for the success of tilapia industry in Buhi was due to sufficient natural food present and good water quality. The lake declared as cleanest lake in the country in 1996 (SCPW 2012), but because of human exploitation such as inadequate aquaculture practices, the lake water suffered which probably results to water deterioration. In fact, Lake Buhi experienced massive mortality or fish kill every year due to change of environmental condition (climate, high ammonia and other parameters) and human activity such as overstocking and overfeeding which resulted to low dissolved oxygen concentration. Furthermore, Fisheries Statistics of the Philippines (FSP, 2017) confirmed that Lake Buhi experienced declining of tilapia production from year 2014-2016.

The potential causes of declining production in aquaculture already determined by several studies. Factors such as change in water parameters, natural food availability, change in weather condition and anthropogenic activities are some factors that describe the fate of aquaculture production in the lake. For instance, the important parameter such as dissolved oxygen levels depend primarily on photosynthetic oxygen generation and plankton respiration (Steel, 1980). The change in water 
parameter which act as stressor (low level of DO)for fish growth and reproduction (Iwama et al. 2000) which resulted to high mortality or fish kill. This preliminary study was made to;(i) investigate the importance of natural food and water parameters in aquaculture system in Lake Buhi; (ii) determine its relationship. (iii); determine the capability of plankton biomass to support the requirements for natural food of tilapia culture in the lake.

\section{Materials AND Methods}

\subsection{Sampling Stations Description}

The study was conducted on June 2017 to September 2017. Four sampling sites were established in the lake as the monitoring site of the study. Station 1 established in Brgy Sta. Cruz wherein fish sanctuary found located at the south east part of the lake. Station 2 is located at the center of the lake or the central water zone serve as the large open fishing navigation in the lake. Station 3 is located at the border Brgy. Ipil, Ibayugan and Tambo wherein the large aquaculture stocking and concentration of fish cages were located, and last station is located at the border of Brgy. Cabatuan and Brgy. Salvacion wherein the Eco-tourism and main outlet of water in the lake.

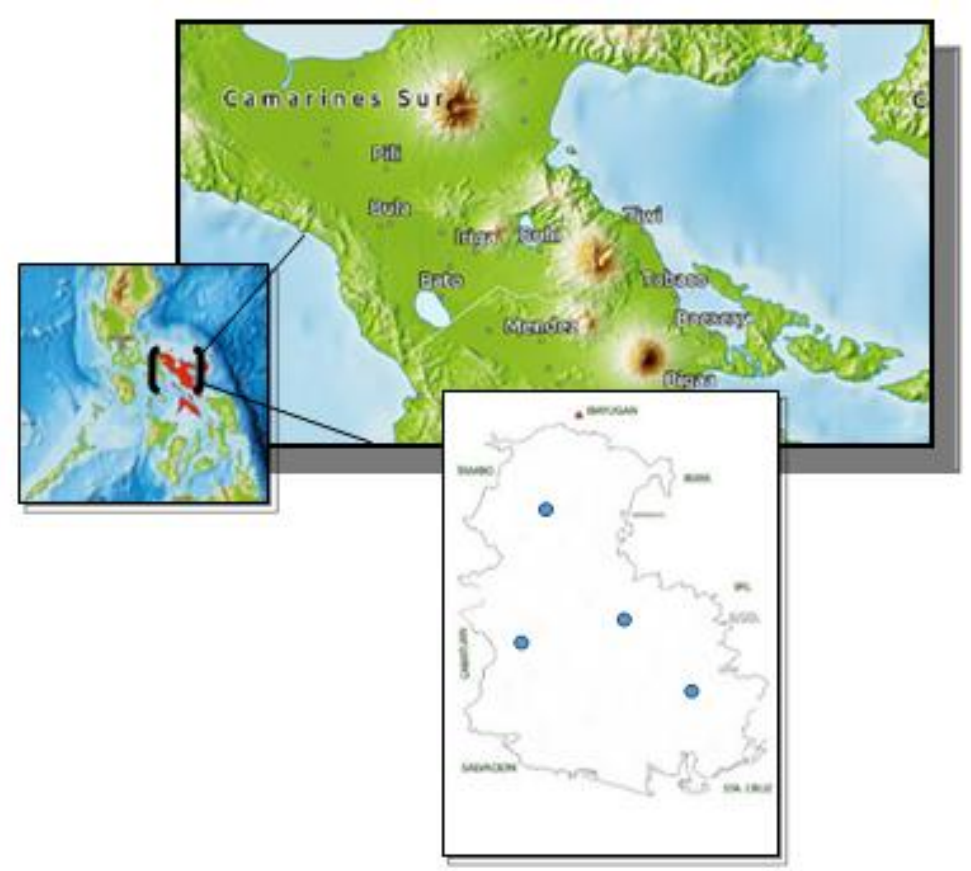

Figure1. Sampling site and stations

\subsection{Plankton Biomass Collection and Analysis}

Plankton collection was carried out using $20 \mu$ mesh sizeplankton net at 5 meters depth. The plankton net was towed twice vertically to collect a total of $500 \mathrm{~mL}$ samples per bottle. Samples were preserved using a 5\% formalin solution and stored in dark bottles for analysis. The gravimetric method (wet weight) was used to determine the plankton biomass. Sample was converted into grams per cubic meter $(\mathrm{g} / \mathrm{m} 3)$.

\subsection{Collection of Physico-Chemical Parameters}

Physico-chemical parameters such as temperature and dissolved oxygen monitored using Hobo DO Logger U26. Light transparency or light penetration was measured using a Secchi disk material. The data collected from HOBO data logger was extracted using the HOBO software and converted into CSV file in Microsoft Excel.

\subsection{Production Per Month}

The partial production per months was accomplished using survey questionnaire for fish cage farmers and operators and collaboration with Bureau of Fisheries and Aquatic Resources Region 5 (BFAR), and the Lake Development Office (LDO-Buhi). 


\section{RESUltS}

\subsection{Plankton Biomass}

A total of $592.711 \mathrm{~g} / \mathrm{m} 3$ average plankton biomass was collected throughout the sampling collection. Average plankton biomass manifested increasing values from $381.28,608.78$ to $679.43 \mathrm{~g} / \mathrm{m}^{3}$ From June to August but decreased in September with $664.25 \mathrm{~g} / \mathrm{m}^{3}$ mean value. Analysis of variance (ANOVA) revealed significant difference $(\mathrm{P}<0.05)$ comparing between sampling months. Using Tukey's pairwise analysis, the month of June is significantly lower with $381.282 \pm 5.2$ (mean \pm standard deviation value) against the rest of the sampling months. Comparative analysis between sampling station revealed no significant $(\mathrm{P}>0.05)$.

Table1. Comparative analysis of Plankton Biomass using (ANOVA) among sampling months

\begin{tabular}{|c|c|c|c|c|c|}
\hline Mean \pm StDev & June & July & August & September & P Value \\
\hline Plankton Biomass & $381.2 \pm 5.2_{a}$ & $608.7 \pm 96.1_{b}$ & $679.4 \pm 186.1_{b}$ & $664.2 \pm 32.9_{b}$ & $0.006^{*}$ \\
\hline Temperature & $30.4 \pm 0.63$ & $29.8 \pm 0.24$ & $28.8 \pm 3.01$ & $29.6 \pm 0.25$ & 0.285 \\
\hline DO & $6.7 \pm 0.32_{a}$ & $6.9 \pm 0.04_{a}$ & $7.0 \pm 0.06_{b}$ & $7.0 \pm 0.12_{b}$ & $0.016^{*}$ \\
\hline Turbidity & $1.37 \pm 0.05$ & $1.38 \pm 0.04$ & $1.39 \pm 0.8$ & $1.33 \pm 0.06$ & 0.63 \\
\hline
\end{tabular}

*Variable is significant in 5\% level; values with different alphabetical superscript are significant

Aside from PB, DO scored significant between sampling months with $0.016 \mathrm{P}$ value coefficient. Highest concentration of DO was observed during August and September months with both $7.0 \mathrm{mg} / \mathrm{L}$ value which significantly higher to June and July sampling with $6.7 \mathrm{mg} / \mathrm{L}$ and $6.9 \mathrm{mg} / \mathrm{L}$ respectively. According to Pillay and Kutty (2005) and Bhatnagar et al., (2004), the ideal DO concentration in aquaculture system range from 5> $\mathrm{mg} / \mathrm{L}$ to maintain the fish homeostasis. Meanwhile, water temperature and turbidity showed no significance with 0.285 degree Celsius and 0.63 turbidity respectively.

The distribution of plankton biomass from every station plotted using the scatter graph to compare the density. Highest plankton biomass observed in station 2 with $622 \mathrm{~g} / \mathrm{m} 3$ while least of PB recorded in station 4 with $576 \mathrm{~g} / \mathrm{m} 3$. The stations 1 and 3 however showed almost similar values with $586 \mathrm{~g} / \mathrm{m} 3$ and $588 \mathrm{~g} / \mathrm{m} 3$ values respectively. However, statistically, it revealed no significant difference between stations with $\mathrm{P}>0.98$ value.

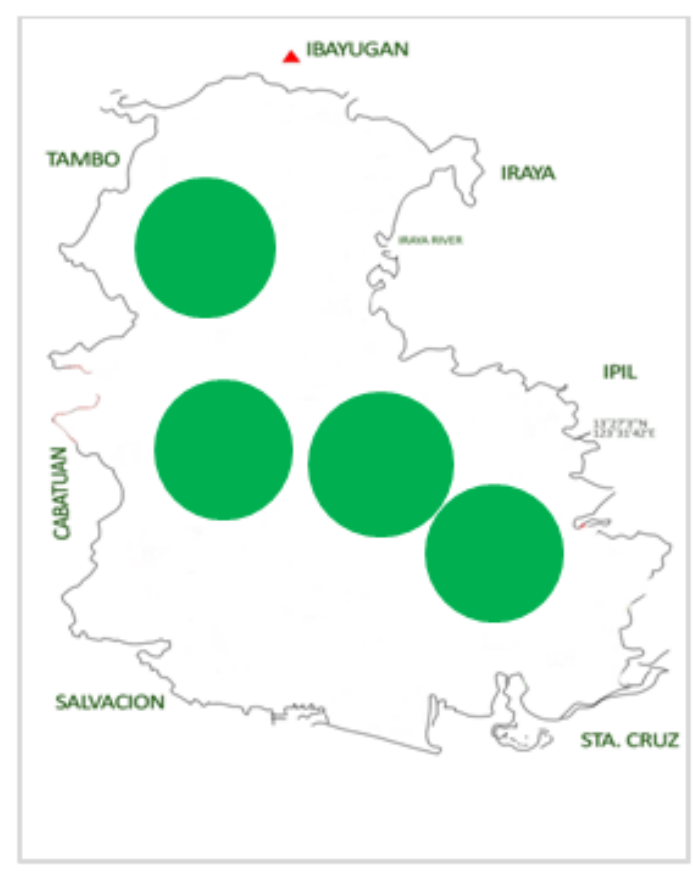

Figure2. Scatter plot of Plankton Biomass collected in each station. 


\subsection{Correlation Between Parameters}

Dissolved oxygen $(\mathrm{mg} / \mathrm{L})$ concentration showed increasing values as the monthly sampling takes place. June sampling showed least DO concentration with $8.37 \mathrm{mg} / \mathrm{L}$ against $8.69,8.78$ and $8.84 \mathrm{mg} / \mathrm{L}$ DO concentration collected in July to September respectively. Adverse to these findings is the result of water temperature with decreasing pattern observed from June to August sampling with 30.50, 30.04 and 28.53 degree Celsius (oC) respectively. Surprisingly, temperature during September sampling showed increasing parallel with the DO pattern.

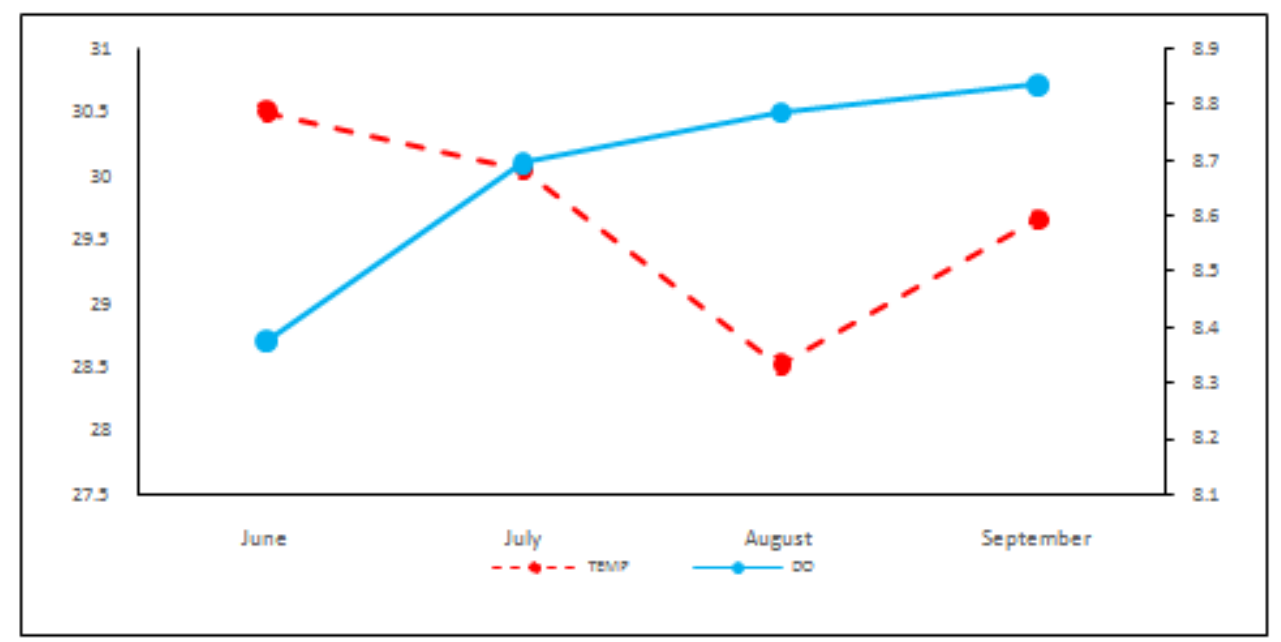

Figure3. Dissolved oxygen and water temperature relationship

\subsection{Tilapia Production against Physico-Chemical Parameters}

The lake experienced increasing values of tilapia production during sampling months with estimated total production of 46.54 ton from June to September. The least estimated production of tilapia culture was experience in June with 2.97 ton followed by July, August and September sampling months with $10.86,14.41$ and 18.30 ton respectively.

The partial production of cultured tilapia per month showed strong positive correlation against DO concentration with 0.97 correlation coefficient value contrast to temperature result with negative correlated values of 0.65 correlation coefficient using Pearson Correlation analysis.

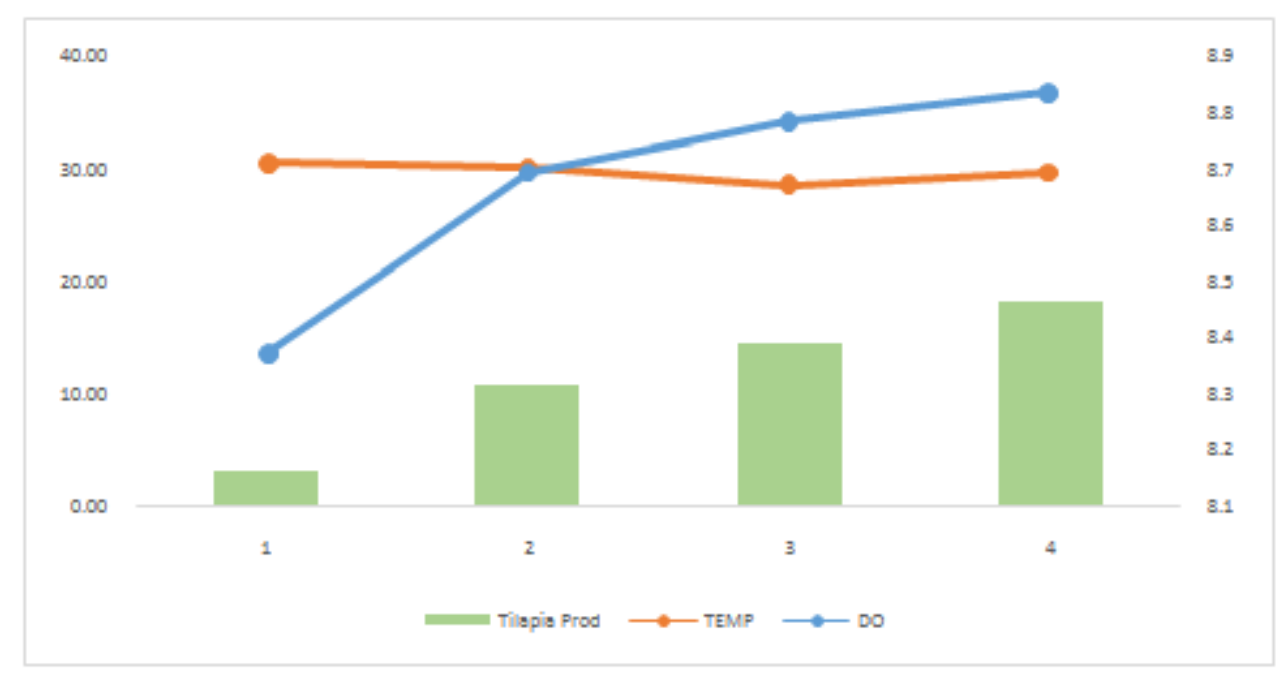

Figure4. Relationship of monthly production against water parameters

Similar result was observed between PB and production of tilapia with strong positive correlation. Regression analysis confirmed the high correlation between PB and production with $0.88 \mathrm{r}$ square value. The monthly production of tilapia in the lake expressed proportionally with the plankton biomass pattern. 


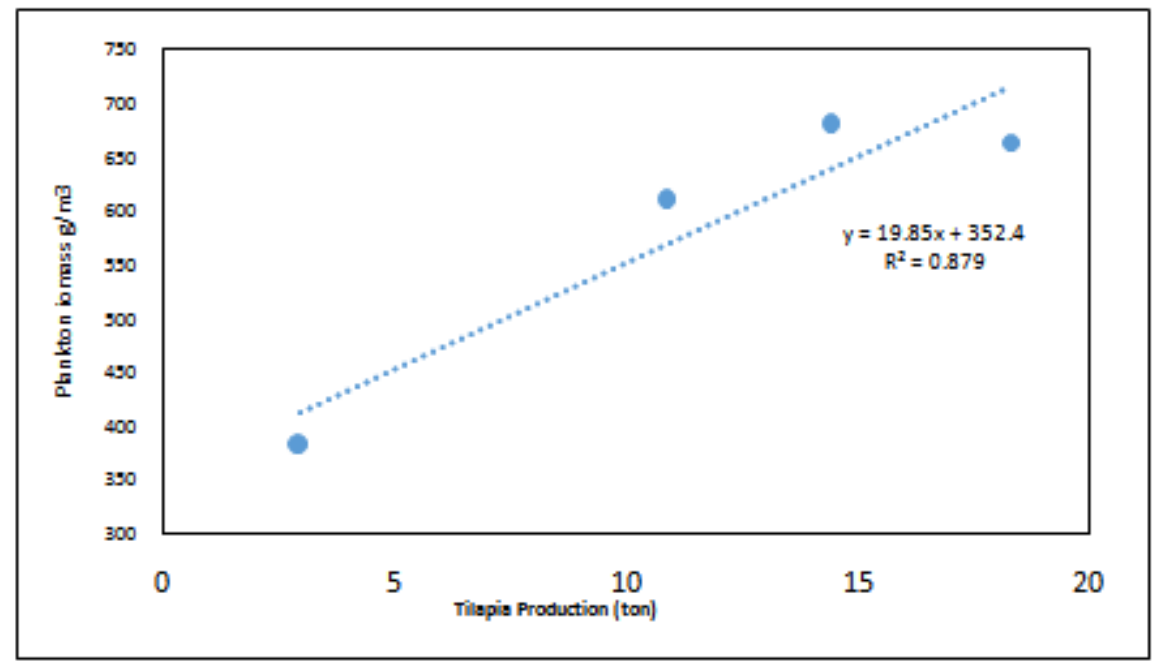

Figure5. Regression analysis between tilapia production and plankton biomass per month

\section{DISCUSSION}

Plankton are crucial in aquaculture as they are the primary food source of many fish in their early stages (Mamaril 2001). The increasing concentration of plankton biomass during sampling months explained by natural and anthropogenic activities in the lake. Despite of high precipitation during sampling months due to southwest monsoon or habagat season, PB continuous to increased concentration from June to September sampling. These pattern can be explained by several factors and indications. First, the high level of organic materials or organic loading in the lake coming from domestic(Vascuquez, 1992)and other natural sources of water through rivers and streams connected to Lake Buhi. Dead fish and organic matters were observed in the lake which also contributes as nutrients for plankton production. According to Demiret al., (2001) cited by Dias et al., (2011) the solid waste in fish cage-culture (uneaten food, feces and mucus) and other soluble waste product will also serve as nutrient for plankton community causes the plankton density blooms. Similar finding was discussed by Guo and Li (2003) wherein the impact of fish cage-culture in the area change the plankton structure and increases the nutrient loading resulted to an increase in phytoplankton biomass and directly influence the biomass of the herbivorous invertebrates such as zooplankton (Dias et al., 2011) .Improper feeding practices of supplemental feeds in fish cage culture also contribute to the nutrient loading which also advantage to plankton and algae species.Second factor is explained by temperature dependent of plankton species. The increase of plankton biomass when temperature decreases can also be related to zooplankton density in the lake. Consequently, the composition of zooplankton affects the biomass relatively by the dominance and abundance of small and large zooplankton species. Colder temperature triggers the dominance of large microfauna while increase in temperature leads to the dominance of small freshwater zooplankton (Rasconi et al., 2015) as well as the phytoplankton and algae which are autotropic. This findings strongly support the results of the study wherein the increasing of plankton biomass was correlated with water temperature. Regression correlation revealed that there was a high negative correlation between PB and water temperature with 0.56 correlation coefficient.

As a result, high plankton biomass provides natural food supply to fish cage-culture in the lake. Rich phytoplankton leads to rich zooplankton density thus creating good survival of young fish and good crop (Russel 1936, Harvey 1950). The results of this study agreed with the conclusion of Smith and Swingle (1939) that plankton and fish production have a direct relationship. Baloloy et. al (2016) also attributed the high plankton density in the lake to the nutrient loading which causes these organisms to thrive accompanied by pollution-tolerant species of algae. The plain distribution of plankton biomass in the study indicates good quantity and quality of natural food present in the lake. Therefore, these findings strongly accept the study and recommendation of Cuvin-Aralar (2012) on the skip feeding (artificial feeds) as an alternative strategy in good production of tilapia farming in Lake Buhi. The purpose of feeding strategy is to minimize the loading of artificial feeds to avoid water deterioration that causes high fish mortality. 
The amount of DO can also be associated to the temperature wherein the solubility of oxygen decreases as temperature increases (Wetzel 2001). Furthermore, the success of photosynthetic production? need ta po magprovide ning numbers and stats kung igwa kita tgmean kaini.

\section{CONCLUSION}

Fish production is influenced by many factors such as the natural food availability and water parameters. Despite high plankton biomass noted in the study, density and biomass of plankton should be maintained at specific levels to avoid extreme algal bloom which is dangerous in any aquatic environment especially during die-off of autotropic organisms. Since the lake water is eutrophic and abundant in natural food, artificial or supplemental feeds can be reduced to avoid water deterioration that causes high fish mortality. This will not only be beneficial to the fish cage farmers but also to the lake itself. Therefore, the partial findings of the study confirmed that the eutrophic waters of Lake Buhi had the capacity to support the requirements for natural food consumption of fish cage culture and maintain its optimum water parameters for growth and reproduction.

\section{ACKNOWLEDGEMENT}

This study was financially funded by Department of Science and Technology (DOST). The author would also like to thank the Bicol University Tabaco Campus, Local Government of Buhi, Lake Developmen Office Buhi, Monicipal Office of Agriculture, Depatment of Natural Resources 5 (DENR) , Bureu of Fisheries and Aquatic Reseources (BFAR) and Mediado and Repatacodo Family during the collection of sampling.

\section{REFERENCES}

[1] Baloloy, A.B., Guzman, M.A., Perez, T., Salmo, S., Unson, J.R., Baldesco, J., Plopenio, J. 2015. 1Department of Environmental Science, Ateneo de Manila University, Loyola Heights, Quezon City, Philippines

[2] Bhatnagar, A., Jana, S. N., Garg, S. K.; Patra, B. C., Singh, G. and Barman, U.K. 2004, Water Quality Management in Aquaculture, In: CCS Haryana Agricultural, Hisar (India); Pp: 203-210.

[3] Cuvin-Aralar, M.L, Gibbs, P., Palma, A., Andayog, A and Noblefranca, L. 2012. Skip feeding as an Alternative Strategy in the Production of Nile Tilapia Oreochromisniloticus(Linn.) in Cages in Selected Lakes in the Philippines. Philippine Agricultural Scientist Vol. 95 No. 4, 378-385.

[4] Demir, N., Kirkagac, M. U.,Pulatsu, S. \&Bekcan, S. 2001. Influence of trout cage on water quality, plankton and benthos in an Anatolian Dam Lake. The Israeli Journal of Aquaculture-Bamidgeh 53:115-127.

[5] Dias, J.D., Takahashi, E.M., Santana, N.F., and Bonecker, C.C. 2011. Impact of fish cage-culture on the community structure of zooplankton in a tropical reservoir. Programa de PósGraduaçãoemEcologia de AmbientesAquáticosContinentais, Nupélia, UniversidadeEstadual de Maringá, Av. Colombo,5790, 87020900 Maringá, PR, Brazil.

[6] Gindelberger, B. 1981. Fishery Management in Camarines Sur Philippines Why "sinarapan" almost disappered from Lake Buhi. ICLARM Newsletter 4(3):3-5

[7] Guo, L. \& Li, Z. 2003. Effects of nitrogen and phosphorus from fish cage-culture on the communities of a shallow lake in middle Yangtze river basin of China. Aquaculture 226:201-212.

[8] Harvey, H.W (1950) On the production of living matter in the sea off Plymouth. J mar. Bioj. Ass. U.K, 29, 97-137.

[9] Iwama, G.K, Vijayan, M.M and Morgan, J.D 2000. The Stress Response in Fish. Icthyology, Recent Research Advances 453 pp. oxford and IBH Publishing Co, Pvt.Ltd.

[10] Mamaril A.C. (2001). Zooplankton diversity in Philippine lakes. In CB Santiago, ML Cuvin-Aralar and ZU Basiao (Eds.). Conservation and Ecological Management of Philippine Lakes in Relation to Fisheries and Aquaculture (pp. 81-93). Southeast Asian Fisheries Development Center, Aquaculture Department, Iloilo, Philippines; Philippine Council for Aquatic and Marine Research and Development, Los Baños, Laguna, Philippines; and Bureau of Fisheries and Aquatic Resources, Quezon City, Philippines.

[11] Philippine Statistics Authority.2017. Fisheries Statistics of the Philippines. Republic of the Philippines Volume 25 2014-2016

[12] Pillay, T. V. R. and Kutty, M. N 2005. Aquaculture, Principles and Practices, 2nd Edition. Blackwell Publishing Ltd, Oxford, UK, 2005; Pp: 630.

[13] Rasconi S., Gall A., Winter K., Kainz MJ (2015). Increasing Water Temperature Triggers Dominance of Small freshwater Plankton.pLoS ONE 10(10): e0140449. DOI: 10.1371/journal.pone.0140449. 
Plankton Biomass in Highly Eutrophic Water and Optimum Physico-Chemical Parameters Supported Aquaculture Production in Buhi Lake: A Preliminary Study

[14] Russel, F.S. (1936). Observations on the distribution on plankton animal indicators made on Col. E.T. Peel's yacht "St. George" in the English channel, July, 1935.- J.mar. biol. Ass. U.K., n. ser., 20: 507-522

[15] Steel, J.A., 1980. Phytoplankton models. In: E.D. LeCren and R.H. Lowe-McConnell (Editors), Functioning of Freshwater Ecosystems. Cambridge University Press, Cambridge, pp. 2‘20-227.

[16] Smith, E.V., and Swingle, H.S. 1939. The relationship between plankton production and fish production in ponds. Trans. Am. Fish. Soc. 68: 309-315. doi:10.1577/1548-8659(1938)68

[17] Vasquez, E. 1992. Temperature and Dissolved Oxygen in Lakes of the Lower Orinoco River Floodplain (Venezuela). Rev. Hydrobiol.Trop. pp: 23-33

[18] Wetzel, R. G. (2001). Limnology: Lake and River Ecosystems (3rd ed.). San Diego, CA: Academic Press.

Citation: Sandy Rey B. Bradecina and Mikka Ella M. Cabrera, "Plankton Biomass in Highly Eutrophic Water and Optimum Physico-Chemical Parameters Supported Aquaculture Production in Buhi Lake: A Preliminary Study". International Journal of Innovative Studies in Aquatic Biology and Fisheries, 6(1), pp.17.http://dx.doi.org/10.20431/2454-7670.0601001

Copyright: (C) 2020 Authors. This is an open-access article distributed under the terms of the Creative Commons Attribution License, which permits unrestricted use, distribution, and reproduction in any medium, provided the original author and source are credited. 